\title{
A INFLUÊNCIA DOS SISTEMAS DE ENERGIA ELÉTRICA DAS PEQUENAS CIDADES DO TERRITÓRIO DO SISAL PARA A ORGANIZAÇÃO ESPACIAL (1990 a 2014)
}

\author{
Valdinéia Gusmão Silva1; Onildo Araújo da Silva ${ }^{2}$ \\ 1. Bolsista PROBIC/UEFS, Graduando em Geografia, Universidade Estadual de Feira de Santana, e-mail: \\ neiagusmaogeo@gmail.com \\ 2. Orientador, Departamento de Ciências Humanas e Filosofia, Universidade Estadual de Feira de Santana, e-mail: \\ fssilvafs@hotmail.com
}

Palavras-chave: Energia; espaço; pequenas cidades.

\section{INTRODUÇÃO}

A presente pesquisa intitulada "A influência dos sistemas de energia elétrica das pequenas cidades do Território do Sisal para a organização espacial (1990 a 2014)", procurou analisar o sistema de energia elétrica das pequenas cidades de Valente, Queimadas, Cansanção, Itiúba, Monte Santo, Retirolândia, Quijingue, São Domingos, Barrocas, Teofilândia, Nordestina, Biritinga, Candeal, Ichu, Lamarão, Serrinha, Conceição do Coité, Santaluz, Tucano e Araci que compõem o Território de Identidade do Sisal. O foco da pesquisa se concentrou em analisar a atual configuração do sistema de energia elétrica e sua influência para a configuração espacial das pequenas cidades, através da compreensão de como a expansão da rede de energia elétrica influenciou o crescimento da pequena cidade e implantação do setor produtivo na mesma, mapeando ainda a rede de distribuição e subestações presentes no Território.

Observasse a relevante importância que este sistema possui, apontado como um dos responsáveis pela geração de conforto, segurança e desenvolvimento de um determinado local, esta pesquisa se faz significativa, podendo ter seus resultados posteriormente utilizados para o desenvolvimento de políticas públicas voltadas para o desenvolvimento e aprimoramento de questões sociais e econômicas do Território.

\section{METODOLOGIA}

Os procedimentos metodológicos utilizados foram: construção de um referencial teórico, elaborado com base na revisão de literatura previamente realizada; levantamento de dados sobre a distribuição da rede de transmissão e subestação de energia, sendo estes posteriormente utilizados para a confecção de dois mapas; levantamento de dados referentes à quantidade de domicílios e indústrias consumidoras da rede de energia elétrica, que também foram analisados e tabulados, servindo de base para a elaboração de gráficos. Todos os dados utilizados no desenvolvimento desta pesquisa foram encontrados em sites de órgãos como: IBGE (Instituto Brasileiro de Geografia e Estática) SEI (Superintendência de Estudos Sociais e Econômicos) e COELBA (Companhia de Eletricidade do Estado da Bahia).

\section{RESULTADOS E DISCUSSÕES}

No gráfico 1 foi possível percebermos que no ano de 1991, quatorze das vinte pequenas cidades pesquisadas possui menos de $50 \%$ dos domicílios com energia elétrica. Pequenas cidades como Lamarão (27,74\%), Biritinga (26,43\%), Monte Santo $(22,01 \%)$ Teofilândia $(21,27 \%)$, Quinjingue $(18,63 \%)$ e Nordestina $(15,13 \%)$ registraram números muito pequenos em relação ás demais cidades, observasse que a pequena cidade de Ichu $(58,55 \%)$ demonstra a segunda maior porcentagem de domicílios com energia elétrica. Já se considerando o no de 2000, nota-se que apenas quatro pequenas cidades do Território do Sisal 
ainda possuíam menos de 50\% dos seus domicílios com energia elétrica, comparando-se com 1991, constata-se um relevante aumento nas porcentagens de domicílios com energia elétrica. Quando analisamos o ano de 2010, notamos que, diferentemente do observado no ano de 1991, todos os municípios no Território do Sisal já apresentavam mais de 50\% dos domicílios com energia elétrica e somente quatro pequenas cidades possuíam porcentagens menores que 90\%: Araci (88,95\%), Nordestina (88,76\%), Queimadas $(88,75 \%)$ e Quinjingue $(84,33 \%)$.

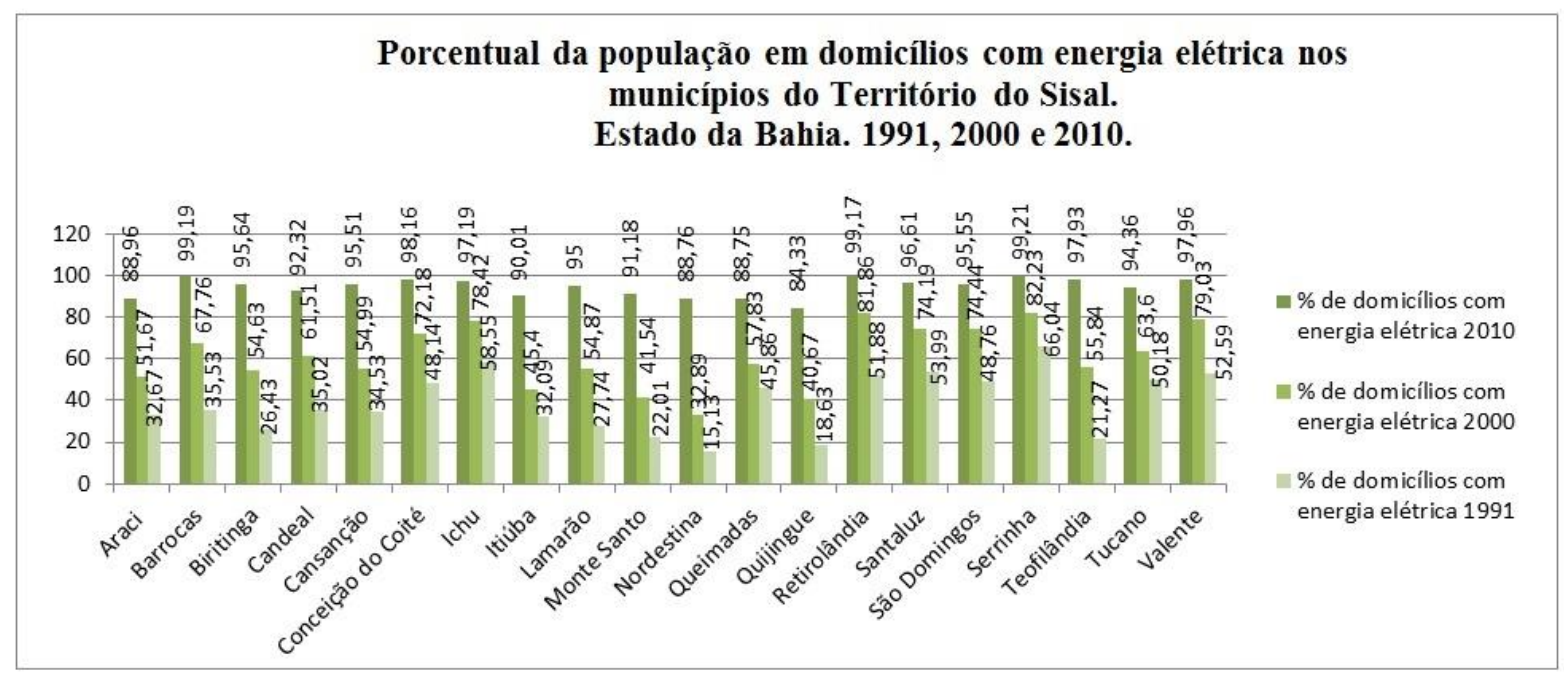

Gráfico 1 Fonte: Atlas Brasil, 2015 Elaboração: SILVA, V.G. 2015.

Desde o ano de 1991 os municípios do Território do Sisal têm mostrado uma ampliação dos seus setores produtivos, em algumas pequenas cidades como Biritinga, Ichu, Monte Santo, Nordestina e Serrinha o número de consumidores industriais mais que dobrou entre os anos de 1991 e 2010. Tendo como exemplo a pequena cidade de Biritinga, que antes possuía apenas dois consumidores industriais e passou para vinte e seis no ano de 2010 . Quatro pequenas cidades se destacam quanto ao número de consumidores industriais no ano de 2010; Conceição do Coité (172), Serrinha (143), Santaluz (59) e Valente (55). Diante do gráfico 2 é possível se afirmar que todas os municípios que compõem o Território do Sisal exibem ampliação dos setores produtivos, com exceção da pequena cidade de Barrocas, uma vez que os dados dos anos de 2000 e 1991 não estão disponíveis.

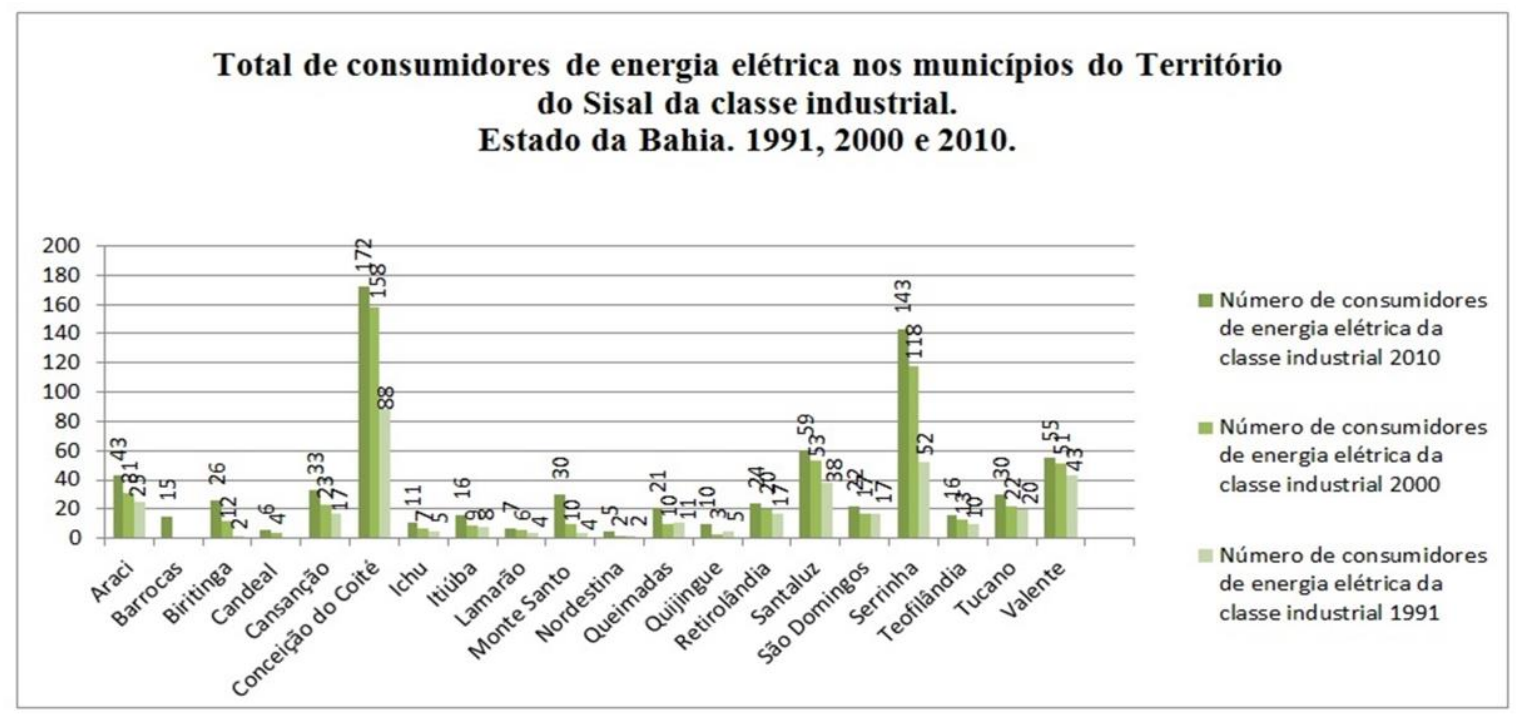

Gráfico 2 Fonte: SEI, 2015 Elaboração: SILVA, V.G. 2015 
Todos os municípios do Território do Sisal apresentam ao menos uma rede de distribuição, como é constatado em três pequenas cidades. Já outras seis pequenas cidades são atendidas por duas redes de distribuição. Apenas dois municípios dispõem de quatro redes e também somente duas possuem cinco redes de distribuição. Enquanto que Serrinha se destaca com nove redes de distribuição de energia elétrica.

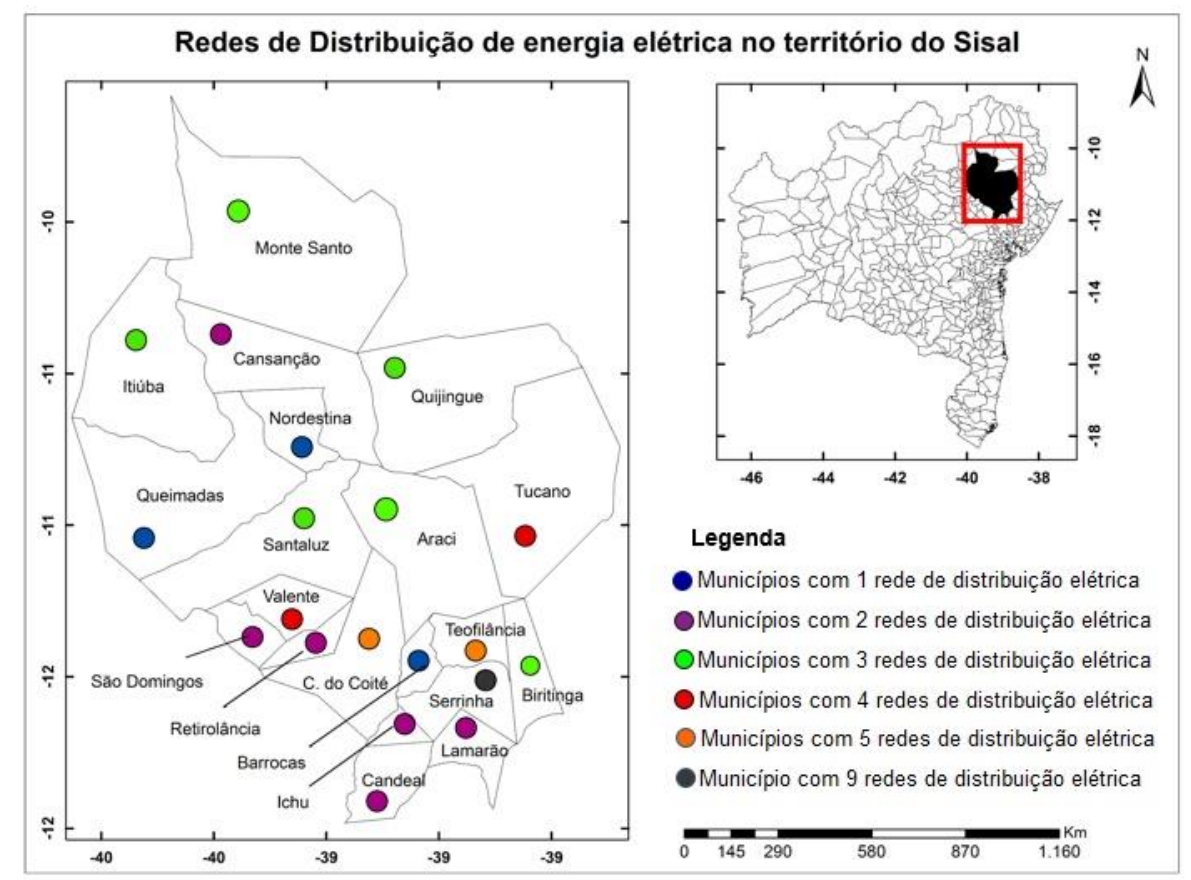

Mapa 1 Fonte: Limite político-administrativo Sig-Bahia, 2003 Elaboração: SILVA,V.G. 2016

O território do Sisal é atendido por quinze subestações, sendo que seis não estão localizadas no Território do Sisal, estando instalado nos municípios de Santa Bárbara, Senhor do Bonfim, Ponto Novo e Euclides da Cunha. Os municípios que constituem o Território do Sisal e não apresentam subestações em seus limites, são atendidos pelas subestações mais próximas. Todo o Território do Sisal é atendido por redes de distribuição e subestações (mesmo que estas não estejam localizadas no próprio território).

Constata-se também um significativo aumento no número de consumidores da classe residencial fato que podemos atribuir à implantação do Programa Luz para Todos, que segundo o Ministério de Minas e Energia (MME) tem como foco principal acabar com a exclusão elétrica no Brasil; junto com o Programa Tarifa Social, que ainda segundo o MME, visa descontos na conta de energia elétrica para famílias classificadas como de baixa renda.

A relação existente entre a criação dos Programas e o aumento de consumidores é perceptível, visto que o grande aumento acontece quase que ao mesmo tempo em que os Programas são implantados em 2003 e 2002 (Luz para Todos e Tarifa Social, respectivamente).

Avalia-se ainda, que provavelmente o considerável aumento da instalação de atividades voltadas para o setor produtivo, também está ligada a expansão da rede de energia elétrica no Território do Sisal, uma vez que para essas atividades possam ser desenvolvidas a energia elétrica é indispensável, pois os instrumentos utilizados em tais atividades são quase que totalmente dependente da eletricidade. 


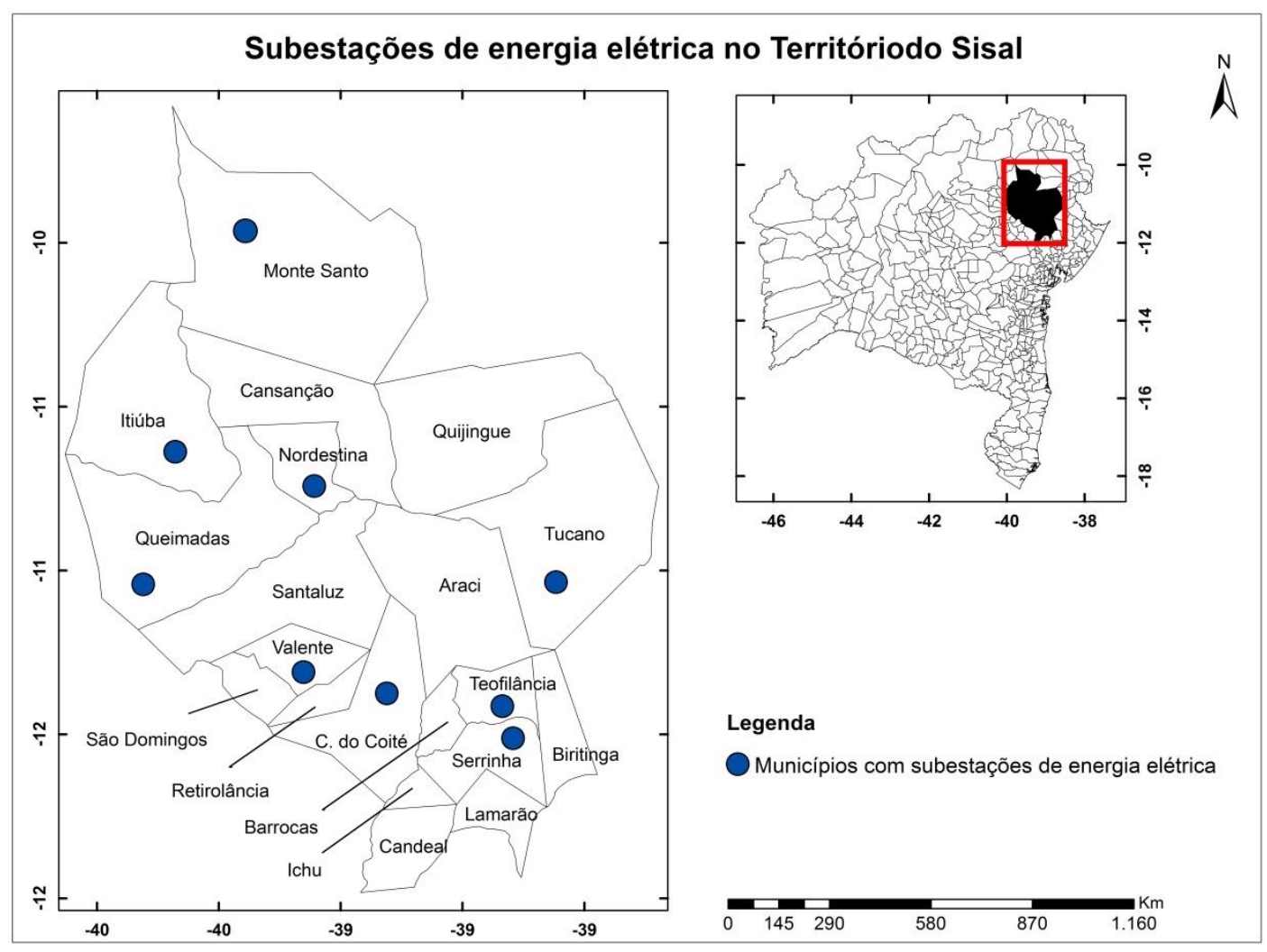

Mapa 2 Fonte: Limite político-administrativo Sig-Bahia, 2003 Elaboração: SILVA,V.G.

\section{CONCLUSÃO}

Observou-se que o Território do Sisal possui uma rede de energia elétrica que atende as necessidades do Território, sendo sua expansão de grande contribuição para a implantação de atividades ligadas ao setor produtivo e consequentemente pelo o cenário de crescimento econômico de diversas pequenas cidades ao longo dos anos de 1991 a 2014.

Fundamentados nos gráficos gerados no decorrer da pesquisa, através dos dados coletados, considera-se que a criação de programas como a Tarifa Social assume um papel importante nesse Território, onde grande parte dos domicílios se enquadra nos critério de possíveis beneficiários. Porém um estudo mais aprofundado sobre a importância deste programa acredita-se ser significativo.

Por fim, considera-se então que a expansão do sistema de energia elétrica, juntamente com a implantação de políticas públicas que visão a extinção da exclusão do sistema elétrico são em grande parte organizadores da atual configuração espacial do Território do Sisal.

\section{REFERÊNCIAS}

ABRADEE, A distribuição de energia. Disponível em: http://www.abradee.com.br/setor-dedistribuicao/a-distribuicao-de-energia . Acesso em 10 de outubro 2015.

ANEEL. Atlas de energia elétrica do Brasil. $3^{\mathrm{a}}$ ed. Brasília: ANEEL. 2008. 236 p.

ARAUJO. Alessandra Oliveira. Redes e centralidades em Feira de Santana (BA): O Centro de Abastecimento e o comércio do feijão. Feira de Santana, BA: UEFS, 2014.132p. CORREAA, Roberto Lobato. As pequenas cidades na confluência do urbano e do rural. GEOUSP-Espaço e tempo, São Paulo. n 30, pp. 05-12. 2011.

DIAS, Leila Christina. Redes: emergência e organização. In__Geografia: Conceitos e temas. 4.ed. Rio de Janeiro: Bertrand, 2000. 352p.

OLIVEIRA, J.E.T de. Energia elétrica. Disponível em: http://www.migalhas.com.br/dePeso/16,MI47946,31047-Energia+Eletrica. Acesso em 18 de novembro de 2015. 